\title{
NARCOTIC-REINFORCED RESPONDING: A RAPID EVALUATION PROCEDURE
}

\section{J. H. WOODS}

Departments of Pharmacology and Psychology, University of Michigan, Ann Arbor, Michigan 48109 (U.S.A.)

(Received September 7, 1978; in revised form May 16, 1979)

\section{Summary}

Rhesus monkeys were conditioned to lever press for intravenous injections of codeine. The self-injection behavior was brought under the control of a schedule of drug delivery and access to the codeine schedule was made available twice each day. Subsequently, a variety of doses of codeine and saline were compared to the dose used to condition and maintain self-injection responding. Each change in drug condition was maintained for only a single experimental session. The procedure is recommended for rapid evaluation of drugs for their capacity to reinforce self-injection behavior.

\section{Introduction}

This paper describes a rapid procedure for identifying potential narcotic analgesics as reinforcers of drug-taking behavior. The rapidity of assessment of new drugs can be greatly increased by the use of subjects already conditioned to self-inject drugs. The new drug is exchanged as the reinforcer for the drug used first to condition and subsequently to maintain drug selfinjection responding. Investigations using substitution techniques have been employed to examine a variety of narcotics and narcotic antagonists in rhesus monkeys (see refs. 1 - 3, for example). The present assessment procedure has the advantage of a relatively more rapid examination of different doses of a new drug. Otherwise, its features are similar to those used previously with narcotics and other pharmacological classes of drugs (see refs. 4 and 5 , for example). We are using this procedure as a complement to procedures used to evaluate potential narcotic analgesics for physiological dependence $[6,7]$.

A successful reinforcer assessment must be rapid and free of criterion errors (i.e. false positives or false negatives). A false positive result in an assessment procedure would presumably arise if the direct (elicited) effects of the new drug produced rates of responding similar to those observed with reinforcing drugs. The procedure described here uses a schedule of drug 
delivery that maintains very high rates of responding followed by very low response rates during periods of correlated, signalled extinction. These response patterns may be more improbable with direct drug effects, and this schedule may thus reduce the changes of false positives (see refs. 1 and 8 , for example). In addition, frequent saline-exchange probes are included, which rapidly reduce rates of responding and insure against the possibility that stimuli other than drug delivery are maintaining responding.

On the other hand, false negative results would occur if a drug capable of maintaining rapid rates of responding failed to do so. In procedures such as those described above, the reinforcer dose is positively related to rate of responding over a restricted range of doses. Further increases in dose lead to decreases in drug-reinforced responding [8-10]. Hence, a failure to identify a drug as a reinforcer might be due to the examination of an inappropriate set of doses (either too high or too low). With the present procedure, large ranges of doses, usually including doses sufficiently high to induce directly observable changes in behavior (for example, sedation), were used to insure against this type of false negative result.

The present communication describes the conditioning procedure and initial results with codeine. These results are compared with other procedures to establish relative reliability and speed of assessment.

\section{General methods}

\section{Subjects}

The subjects were six (male and female) rhesus monkeys (Macaca mulatta) weighing between 4 and $8 \mathrm{~kg}$. Prior to surgery, monkeys were anesthetized using ketamine $(10 \mathrm{mg} / \mathrm{kg}$ i.m. $)$ and pentobarbital $(15 \mathrm{mg} / \mathrm{kg}$ i.v.). Each subject was implanted with an indwelling silicone (I.D. $0.079 \mathrm{~cm}$, O.D. $0.239 \mathrm{~cm}$ ) catheter (Rodhelm Reiss Co., Belle Mead, N.J.) in either the right or left internal or external jugular veins, or the right or left femoral veins. Veins were used successively as needed. Details of the essential procedure have been reported [11].

Each monkey was given free access to water and fed approximately $\mathbf{5 0}$ g of Purina Monkey Chow, 45 minutes prior to each experimental session. For the control of tuberculosis, isoniazid $(0.5 \mathrm{ml}$ of a $80 \mathrm{mg} / \mathrm{ml}$ solution) was given to each subject daily on a sugar cube.

\section{Apparatus}

Each monkey was fitted with a stainless steel harness connected by a swivel to a jointed arm containing the catheter. The entire assembly (as essentially described in Figs. 1 and 2 of ref. 11) was attached to the back of the cubicle. Liquid flow through the catheter was accomplished using a roller infusion pump (Model MHRK 55; Watson and Marlow Co., Falmouth, Gt. Britain). The cubicle $(78 \times 78 \times 91 \mathrm{~cm})$ served as both experimental chamber and living quarters for each subject. 
A hinged metal stimulus panel $(23 \times 15 \times 13 \mathrm{~cm})$ was located $15 \mathrm{~cm}$ above the floor on the front wall of the cubicle. On the stimulus panel facing the subject were three $7 \mathrm{~W}$ stimulus lights. The lights were covered by red or green reflectors. The three lights were $3 \mathrm{~cm}$ apart centered on the panel; the center reflector was green and outside reflectors were red. Below the lights were two response levers (Model 121-07; BRS-LVE, Beltsville, Maryland) 6 $\mathrm{cm}$ apart, $4 \mathrm{~cm}$ from the bottom of the panel, centered on the panel.

Experimental parameters and on-line data analysis [12] were provided by a computer (PDP-5 or PDP 8/I; Digital Equipment Corp., Maynard, Mass.) which was located in an adjoining room along with cumulative recorders, a closed circuit TV and recording system, and peripheral hardware.

\section{Procedure}

\section{General shaping}

Following postoperative recovery, experimental sessions were run twice daily with approximately $4 \mathrm{~h}$ between sessions. Each subject was trained to respond by placing a raisin on top of the right response lever. A downward displacement of the lever requiring 10-15 g defined a response. In the initial session, each response on the right lever in the presence of the right stimulus light was followed by a 5 -sec injection, producing $1 \mathrm{ml}$ of a solution adjusted, according to body weight, to deliver $0.32 \mathrm{mg}$ codeine phosphate per $\mathrm{kg}$ (molar dose $=7.5 \times 10^{-7} / \mathrm{kg}$ ). The session was terminated after $130 \mathrm{~min}$ or 13 injections, whichever came first.

When the monkeys took all the available injections on at least two successive sessions, a 10-sec time out was added following each drug injection. During the timeout, responses were ineffective and stimulus lights were not lit. The timeout duration was sequentially increased as follows: 10, 30, $60,180,360$, and finally to $600 \mathrm{sec}$. When all available injections were taken with a 600-sec timeout following each injection, the number of responses (fixed ratio, FR) required to produce the 5 -sec injection was sequentially increased in small response increments from 1 to 30 . The criterion for increasing FR size was that a relatively high rate of responding was maintained with increasing fixed ratios. Following a small number of sessions at the maximal FR requirement and timeout duration, a probe procedure was initiated.

\section{Substitution procedure}

Prior to a monkey's exposure to other codeine doses, a solution of saline $(0.9 \% \mathrm{NaCl})$ was substituted for codeine on each fourth session for a total of either six saline substitutions or until the FR rate of response was less than 0.2 responses/sec.

When this criterion was met, four of the six monkeys were exposed to different doses of codeine. A different dose was substituted on each fourth session. A range of doses in half-logarithmic divisions was examined; duplicate 
observations at each dose were obtained in each of four monkeys. The lowest dose examined was specified as a dose that would have no greater effect than saline. The highest dose examined was specified as one controlling a lower rate of responding than that of the next lower dose (as indicated earlier, often high doses of reinforcing drugs are accompanied by low rates of responding (see, for example, ref. 13).

\section{Results}

Figure 1 shows a set of performances for a single, representative monkey as the contingencies controlling codeine reinforcement were gradually changed to the final conditions of the experiment. When responding did not occur within the first few sessions, responding was induced by taping raisins on the lever (sessions 1-3). When responding occurred regularly, and all of the injections were taken without raisins, the timeout and then fixed-ratio
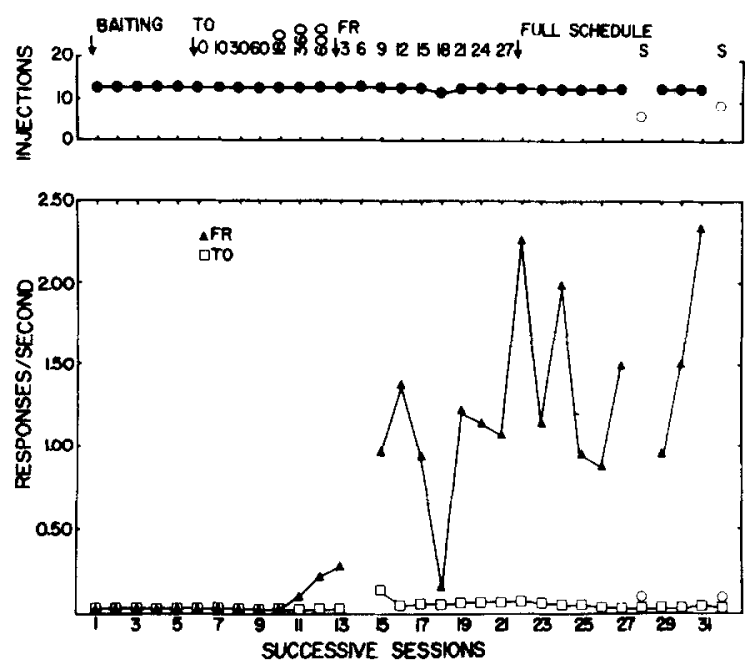

Fig. 1. The acquisition of codeine self-injection responding in one monkey. The upper portion of the figure shows the number of injections taken across successive sessions. Sessions were started by illuminating the fixed-ratio cue light above the right lever, and completed after 130 minutes or 13 injections, whichever came first. In the caption above the upper portion, the timeout (TO) durations are given in seconds. These were increased and were maintained at a final value of 600 seconds. The timeout began immediately after the 5-sec injection. The fixed-ratio (FR) requirement was successively raised to 30 , and these schedule parameters are also shown in the caption above the upper portion of the figure. Thus, the final schedule of reinforcement was a fixed-ratio of 30 which produced a $0.32 \mathrm{mg} / \mathrm{kg}$ per injection of codeine followed by a 600 -sec timeout. On sessions 28 and 32 , codeine was replaced by saline. The lower portion of the figure shows the rates of responding during the fixed-ratio portion of the session (triangles) as well as during the timeout portion (squares). Rates of responding during the sessions for saline (28 and 32) are indicated by circles. Data were lost from session 14. 
requirements were increased to the final conditions of the experiment. Rates of responding increased to over 1 response/sec in the presence of the fixedratio cue light. During the timeout, responding occurred at very low rates (Fig. 1). Also, responding virtually never occurred on the inactive lever. Thus, for this monkey in particular, and the majority of other monkeys in the study, high rates of responding at substantial fixed-ratio requirements were obtained in less than three weeks following catheterization.

When saline was substituted for codeine in this monkey (sessions 28 and 32, Fig. 2), rates of responding were immediately very low. This was somewhat atypical, as can be seen when a larger number of monkeys was examined (Fig. 2). Upon the initial introduction of saline, rates of responding were reduced, and there was a gradual further decline in responding over the first three saline exposures. It should be emphasized that there were no external cues to the change of reinforcement conditions. Figure 3 shows representative cumulative records of fixed-ratio performances for six
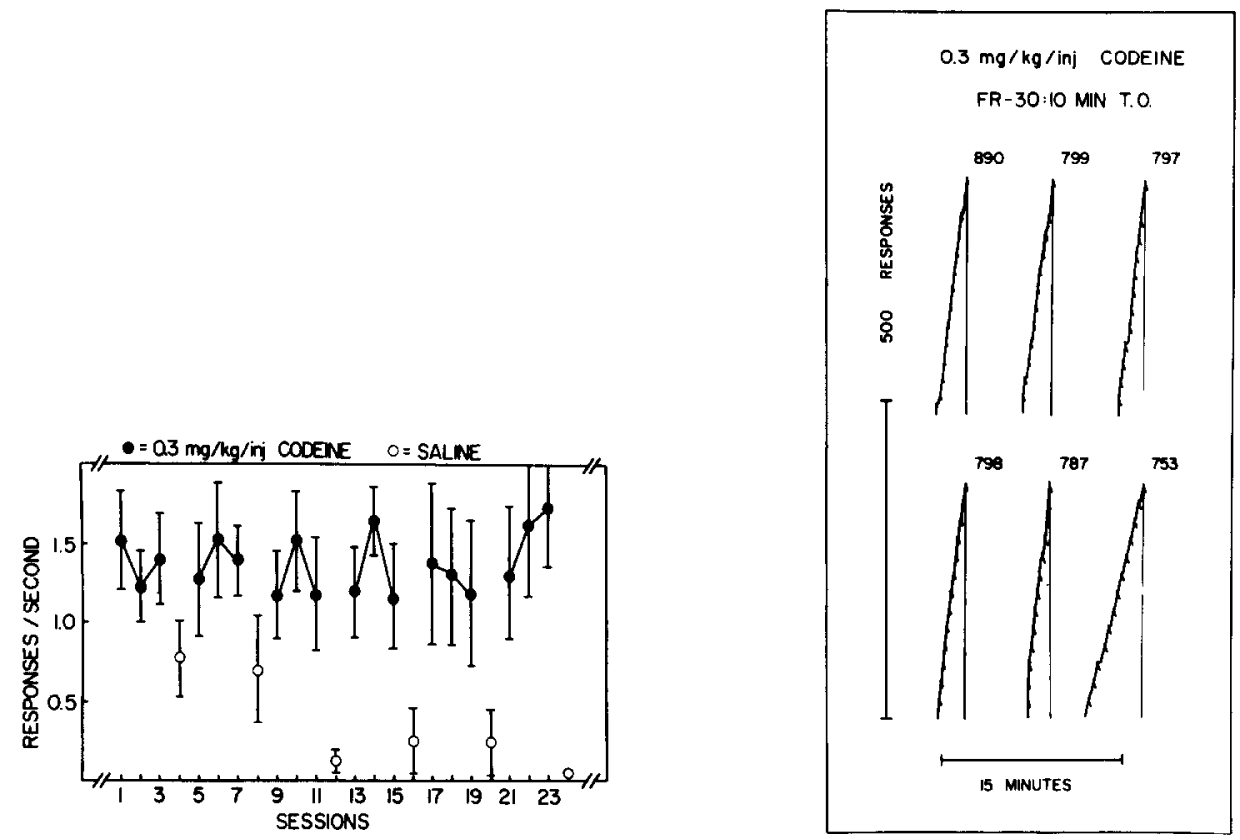

Fig. 2. The fixed-ratio rates of responding in six rhesus monkeys under a fixed-ratio 30 , timeout 600 -sec schedule of codeine reinforcement. Sessions in which codeine was used to maintain self-injection responding are shown as closed circles; when saline replaced codeine, as open circles. In each case, the brackets indicate \pm 1 standard error of the mean. The data represent the first six saline probes with these monkeys.

Fig. 3. Cumulative records of representative individual performances of six monkeys under the final conditions of codeine delivery. Each response steps the recorder pen up; oblique deflections of the pen indicate injections. The paper drive did not run during injections or timeouts; nor were responses recorded during injections or timeouts. Numbers above the records designate individual monkeys. 

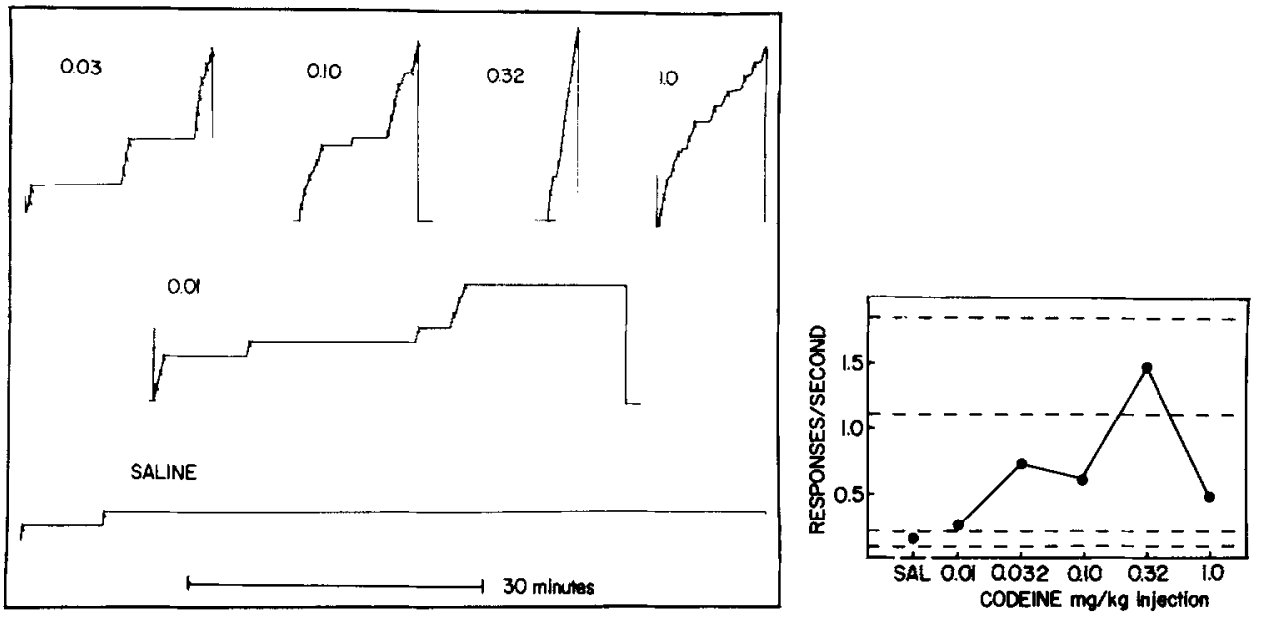

Fig. 4. Schedule-controlled performances at different doses of codeine and saline. Individual responses move the recording pen up; the oblique deflections of the pen indicate the delivery of an injection. The paper drive did not run during injections or timeouts; nor were responses recorded during these periods. The major effect of changing the dose was to influence the pause between injections and the FR-30 response sequences.

Fig. 5. Summary of the effects of dose on the fixed-ratio rates of responding maintained by the various doses of codeine and by saline $(n=4)$. Each point is the average of two observations in each of four monkeys; the dashed lines give the standard error of the average of the duplicated values of saline and $0.32 \mathrm{mg}$ of codeine per $\mathrm{kg}$.

monkeys under the terminal contingencies of codeine delivery. With each animal a slight pause in responding after each timeout was followed by a sustained high rate of responding during the illumination of the light associated with the fixed-ratio component of the schedule. Further, the high rates of responding were maintained over the entire session of approximately two hours.

When the dose of codeine was increased or decreased, rates of responding were reduced (Fig. 4). Figure 4 shows the pattern of responding by an individual monkey produced by the various doses of codeine and saline. As the dose was varied, there were marked changes in the lengths of the pauses prior to the initiation of the sustained sequence of responding that resulted in injections. Figure 5 shows the summarized data from a series of duplicated observations at each condition in each of four monkeys. The rates of responding were reliably maintained by doses from 0.03 to $1.0 \mathrm{mg} / \mathrm{kg}$; the maximal rates being maintained by $0.32 \mathrm{mg} / \mathrm{kg}$ per injection.

\section{Discussion}

Codeine maintained maximum rates of responding at or over 1 response/ sec at $0.32 \mathrm{mg} / \mathrm{kg}$ per injection. These rates of fixed-ratio responding are 
higher than those maintained by codeine in other experiments (see, for example, refs. 2 and 9). This difference is in part due to the use of the timeout between injections. The timeout imposes a limit on the rate of drug delivery and may, by this mechanism, or others [14], sustain higher rates of drug-reinforced responding. The imposition of timeouts of ten minutes duration may also shift the dose-rate relationship under fixed-ratio schedules to the right by an order of magnitude. Without timeouts, the maximum rate of responding is obtained in the $0.01-0.03 \mathrm{mg} / \mathrm{kg}$ range (for example, Fig. 1 of ref. 9), whereas in this experiment the maximum rates were obtained at 0.32 $\mathrm{mg} / \mathrm{kg}$ per injection. Thus, by comparison, timeouts also suppress responding at lower codeine doses.

The procedure used in this experiment is relatively rapid in its assessment of a drug. For comparison, Downs and Woods [9] exposed rhesus monkeys to ten successive daily sessions before doses were changed. Hoffmeister and Schlichting [2] maintained monkeys on each dose for six daily sessions before attempting to recover prior drug-reinforced responding. It is likely that under previous procedures, ten daily sessions would be necessary to obtain an evaluation of a particular dose and recover an appropriate control rate of responding. The present procedure allows individual doses to be examined every fourth session (two days). The maximum rate of dose evaluation must be limited by the time required for dissipation of the direct effect of drug. The present procedure does not seem to have reached that limit.

Another way in which this procedure gains rapidity of evaluation is with the use of conditioned animals. Development of stable performance under the terminal contingencies of the experiment required 3-4 weeks, which is comparable to other limited-access substitution procedures. When naive animals are used, and relatively longer periods of drug access are provided, evaluation of a single dose often requires 2-4 weeks. An additional advantage of limited access conditions to codeine in this experiment is that smaller amounts of drug are required for a complete drug evaluation than with other procedures. We are examining whether we can reduce the amounts further by using smaller doses per injection to maintain self-injection behavior.

A possible disadvantage of using conditioned animals is that the results may depend in some way on the particular drug used to maintain drugreinforced responding. There is some evidence that history of drug administration or self-administration may influence the rate of drug-reinforced responding as well as the classification of drugs as reinforcers (see, for example, ref. 15).

\section{Acknowledgements}

This research was supported by NIDA Grant DA-00254. A portion of these data was reported at the scientific meeting of the Committee on 
Problems of Drug Dependence, Boston, July, 1977. The excellent technical assistance of Wendy Pound was appreciated greatly. The editorial comments of Gail Winger, Alice Young, and Seymore Herling improved the manuscript, and Isabel Herling prepared the manuscript well.

\section{References}

1 J. H. Woods and C. R. Schuster, in T. Thompson and R. Pickens (eds.), Stimulus Functions of Drugs, Appleton-Century-Crofts, New York, 1971, p. 163.

2 F. Hoffmeister and U. U. Schlich ting, Psychopharmacologia, 23 (1972) 55.

3 C. R. Schuster and R. L. Balster, in H. W. Kosterlitz, H. O. J. Collier and J. E. Villarreal (eds.), Agonist and Antagonist Actions of Narcotic Analgesic Drugs, University Park Press, Baltimore, 1973, p. 243.

4 G. Winger, M. L. Stitzer and J. H. Woods, J. Pharmacol. Exp. Ther., 195 (1975) 505.

5 R. R. Griffiths, G. Winger, J. V. Brady and J. D. Snell, Psychopharmacology, 50 (1976) 251.

6 M. H. Seevers and G. A. Deneau, in W. S. Root and F. G. Hofman (eds.), Physiological Pharmacology, Vol. I, Academic Press, New York, 1963, p. 565.

7 W. R. Martin, C. G. Eades, W. O. Thompson, J. A. Thompson and H. G. Flanary, J. Pharmacol. Exp. Ther., 189 (1974) 759.

8 S. R. Goldberg, J. Pharmacol. Exp. Ther., 786 (1973) 18.

9 D. A. Downs and J. H. Woods, J. Pharmacol. Exp. Ther., 191 (1974) 79.

10 D. A. Downs and J. H. Woods, J. Exp. Anal. Behav., 23 (1975) 415.

11 G. A. Deneau, T. Yanagita and M. H. Seevers, Psychopharmacologia, 16 (1969) 30.

12 J. H. Moon, J. D. Stark and C. Dok-Sun, DECUS Soc. Symp. Spring, 1973, p. 159.

13 J. H. Woods, in M. A. Lipton, A. DiMascio and K. F. Killam (eds.), Psychopharmacology: A Generation of Progress, Raven Press, New York, 1978, p. 595.

14 H. Leitenberg, Psychol. Bull, 64 (1965) 428.

15 S. R. Goldberg, F. Hoffmeister and U. U. Schlichting, in J. M. Singh, L. Miller and H. Lal (eds.), Experimental Pharmacology, Vol. 1, Futura Press, Mount Kisco, N.Y., 1972, p. 31 . 